\title{
Living in the parallel universe in Australia: public Medicare and private hospitals
}

Published at www.cmaj.ca on Sept. 13, 2005.

$\mathrm{T}$

he decision in the recent Chaoulli court case may presage the development of a nontrivial private sector in the Canadian health care system. Australia models many aspects of its Medicare system on Canada's plan: Australia has a national, universal scheme that is administered, in terms of hospital access and fees, at the State level within a national framework. But in Australia, a prominent private system exists alongside the public system. In 2003/04 about $40 \%$ of all hospital admissions were to private hospitals.

About $43 \%$ of the people residing in Australia have private health insurance. This dual system has deleterious implications for the equity and efficiency of the health care system, and similar ill effects could occur if Canada were to follow the Australian path of health care organization.

The current Liberal federal government in Australia has supported expanding the role of private health insurance. In 1996 it introduced a subsidy to the industry in the form of a rebate against the cost of insurance. Effectively, the government pays $30 \%$ (a larger proportion, for older people) of the cost of any private health-insurance package. The government also introduced other incentives to take out insurance: a higher federal tax (a 1\% surcharge on taxable income) on high-income earners that can be avoided if they take out private insurance; policies to reduce unexpected gaps between bills from hospitals and doctors and the benefit payments from health insurance funds; and the most effective policy, in terms of increasing membership — the 1999 Lifetime Health Cover policy, which encourages Australians to take out health insurance by age 30 and main- tain it life-long. ${ }^{1}$ Higher-income groups seem to have benefited more from these changes than those with lower incomes. ${ }^{2}$

The current net cost of private health insurance coverage for private hospital care for a couple is US\$1000-\$2500 per year, after taking into account the government rebate. Packages at the lower end of the price range have higher "front-end" deductibles and, hence, higher out-of-pocket costs when a person is admitted to hospital. Costlier insurance packages cover better amenities.

Private hospitals have 2 roles in Australia. In the first, they fulfill a supplementary or "topup" function: patients can purchase additional amenities such as single-occupancy room accommodation and better meals. The second and more contentious role is that of an alternative provider of services available in the public sector: patients are able to pay to bypass public waiting lists or to guarantee that their elective surgery shall be performed by their specialist rather than by a surgeon in training. These complementary roles create inequity and (because the private sector contributes very little to surgical training) also militate against comprehensive training for health professionals.

Many surgeons practise in both the public and the private sectors for ideological, financial or convenience-related reasons. Public-sector constraints are such that, inevitably, surgeons are unable to get the operating sessions that they would desire in the public sector; thus, the private sector provides additional scope.

The greater the proportion of time a surgeon spends in the private sector, the less time he or she is available for work in the public sector. Arguably, greater reimbursement in the private sector provides some incentive to delay operations in the public sector so that patients are "forced" to move into the more lucrative private sector.

A reduction in surgical time in the private sector (and publicsector funding constraints) contributes to increased wait times in the public sector. Australian data have shown that in any specialty, the greater the proportion of surgeries performed in the private sector, the longer the public-sector waiting times, and the shorter the waiting times for procedures in private hospitals. ${ }^{3}$ Waiting times currently vary by specialty; for example, the median wait in an Australian public hospital is 46 days for orthopedic surgery, but 60 days for ophthalmology. Relations between the public and private sectors are therefore complex, and the development of private services in Canada could lead to a reduction in access to services similar to that experienced by Australians.

Public and private sectors in Australia are not perfect substitutes for one another. Private hospitals there tend to specialize in elective procedures; for example, $50 \%$ of orthopedic and urologic surgeries are undertaken in private hospitals, whereas almost no neurologic or cardiothoracic surgeries are done in these venues (Table 1). This "division of labour" also sidesteps the scheduling problems inherent to providing emergency services.

Because private hospitals have tended to specialize in elective surgery, Australians still rely on the public sector for their emergency services. Public hospitals have therefore not undergone "ghettoization" into services oriented mainly toward poor people and those who are other- 
wise disadvantaged. This factor has been important to maintaining high-quality services in public hospitals in Australia.

\section{Trends}

Between 1994 and 2004, patient separations (a count of discharges and transfers from hospital and in-hospital deaths that acts as a measure of hospital activity) grew by about 218000 per annum. Of these, about 194000

Table 1: Most frequent patient separations* at private hospitals in Australia, 2001/02

\begin{tabular}{lr}
\hline Diagnosis-related group & Separations \\
\hline Other colonoscopy, same day & 169366 \\
Chemotherapy & 121804 \\
Other gastroscopy for non-major digestive disease, same day & 101092 \\
Major lens procedure & 89251 \\
Renal dialysis & 88807 \\
Dental extraction or restoration & 73776 \\
Knee procedure & 63557 \\
Follow-up after a completed treatment with endoscopy & 51359 \\
Mental health treatment, same day, without ECT & 49189 \\
Other skin, subcutaneous tissue or breast procedure & 36462 \\
Vaginal delivery without a complicating diagnosis & 35532 \\
Abortion with D\&C, aspiration curettage or hysterotomy & 1416233 \\
All other diagnosis-related groups & 2356780 \\
\hline Total &
\end{tabular}

Note: $\mathrm{ECT}=$ electroconvulsive therapy, $\mathrm{D} \& \mathrm{C}=$ dilation and curettage.

*Discharges, transfers and in-hospital deaths.

Table 2: Estimated additional patient separations in private hospitals, 1999-2002

\begin{tabular}{|c|c|c|c|}
\hline Diagnosis-related group & $\begin{array}{l}\text { Additional } \\
\text { separations* }\end{array}$ & $\begin{array}{l}\text { Average } \\
\text { LOS, d }\end{array}$ & $\begin{array}{c}\text { Cost per } \\
\text { separation, A\$ }\end{array}$ \\
\hline Other colonoscopy, same day & 43390 & 1.00 & 630 \\
\hline Major lens procedure & 17330 & 1.02 & 1457 \\
\hline Abortion with D\&C, aspiration curettage or hysterotomy & 16110 & 1.01 & 613 \\
\hline Follow-up after a completed treatment with endoscopy & 15550 & 1.01 & 603 \\
\hline Other factors influencing health status, age $<80 \mathrm{yr}$ & 13240 & 1.54 & 982 \\
\hline Dental extraction and restoration & 12990 & 1.01 & 772 \\
\hline $\begin{array}{l}\text { Other skin graft or débridement procedure without } \\
\text { severe complications or comorbidity }\end{array}$ & 11910 & 1.35 & 1482 \\
\hline Other skin, subcutaneous tissue or breast procedure & 11820 & 1.10 & 919 \\
\hline Sleep apnea & 11180 & 1.02 & 489 \\
\hline Endoscopic procedure for female reproductive system & 9820 & 1.06 & 1079 \\
\hline $\begin{array}{l}\text { Local excision and removal of an internal fixation } \\
\text { device, excluding those in the hip or femur }\end{array}$ & 8230 & 1.30 & 1242 \\
\hline Knee procedure & 7930 & 1.23 & 1388 \\
\hline All other diagnosis-related groups $†$ & 52000 & 3.23 & 2285 \\
\hline Total & 231500 & 2.65 & 1919 \\
\hline
\end{tabular}

Note: $\mathrm{LOS}=$ length of stay, $\mathrm{A} \$=$ Australian dollars, $\mathrm{D} \& \mathrm{C}=$ dilation and curettage.

*Calculated by comparing expected growth based on the pre-1999 trend with the actual growth in the 1999-2002 period (adjusted for underreporting of diagnosis-related group).

†Including diagnosis-related groups that increased or reduced patient separations. health insurance policy changes showed their most concentrated effect. The combined growth across the 2 sectors was about $10 \%$ higher than in previous years, but in public hospitals the rate declined to an annual increase of about 40 000, compared with an increase to about 180000 additional separations at private hospitals. Most of the increase was in same-day or short-stay procedures; numbers in longer-diagnosis-related groups grew relatively little over this period. (Australian National Diagnosis Related Groups classify medical admissions into groups with similar clinical conditions or related diagnoses and therefore similar resource usage. This facilitates comparisons of the activity and performance of hospitals.)

Two key effects explained this differentiation: a shift from the public to the private sector and an increase in overall provision of private hospital services, responding to either unmet need or to created demand. Table 2 shows the 12 diagnosis-related groups with the greatest increase in activity over this period.

The effect of the changes in health-insurance policy is that about 180000 patients per annum have been shifted from the public to the private sector. The Australian government subsidy to private health insurance now costs about $\mathrm{A} \$ 3$ billion per year. If three-quarters of the subsidy is attributed to inpatient care (the approximate proportion of hospital v. "ancillary" insurance), the cost for the 180000 patients shifted to private hospitals is around \$A12 500 per patient, well above the costs of the types of additional patients treated in private hospitals (Table 2).

The overall effect on health expenditure has also been substantial. Before the introduction of the rebate, the health share of gross domestic product (GDP) in Australia was about $8.5 \%$. The current share is about $9.5 \%$, a considerable change in the historic level of health spending (Table 3).

About half of the $1 \%$ increase 
Table 3: Health spending as a percentage of Australia's gross domestic product

\begin{tabular}{lcccc}
\hline & \multicolumn{2}{c}{ Public sector, \% } & Private sector, \\
Fiscal year & Non-rebate & Rebate & $\begin{array}{c}\text { Total, } \\
\%\end{array}$ \\
\cline { 2 - 4 } 1995/996 & 5.6 & 0.0 & 2.7 & 8.4 \\
$1996 / 97$ & 5.7 & 0.0 & 2.8 & 8.5 \\
$1997 / 98$ & 5.8 & 0.1 & 2.7 & 8.6 \\
$1998 / 99$ & 5.8 & 0.2 & 2.8 & 8.7 \\
$1999 / 2000$ & 5.9 & 0.3 & 2.7 & 8.9 \\
$2000 / 01$ & 6.0 & 0.3 & 2.8 & 9.2 \\
$2001 / 02$ & 6.1 & 0.3 & 3.0 & 9.3 \\
$2002 / 03$ & 6.2 & 0.3 & 3.1 & 9.5 \\
\hline
\end{tabular}

*Totals may be affected by rounding.

in health spending as a share of GDP has been driven by the continuation of a secular trend in the growth in the public share of GDP, and about half by the changes in the role of the private sector. Some 0.3 percentage points of the $1 \%$ growth in GDP share is due to government expenditures on the rebate account, and about 0.2 points is due to growth in privatesector expenditure. This is a shift from the pre-rebate picture of relative stability in private-sector share. The increase in private expenditure over the period results in part from increased out-of-pocket expenditures (to meet gaps between rebates and the fees charged by surgeons and hospitals) and to the cost of purchasing the insurance itself (or, more accurately, the increased proportion of the populace who have health insurance).

\section{Conclusion}

The Australian experience with a dual system of health care has been mixed. Certainly, consumers (and the medical profession) welcome and support the wider choices arising from the existence of private hospitals. But this choice has come at the expense of equity, with access to elective surgery particularly affected: those with health insurance have faster access to elective surgery than those without.

A further worrying aspect of policy direction in Australia has been that those with private health insurance have become a group with political influence. Privatehealth-insurance lobbyists have mounted a successful campaign over decades to obtain government financial support for their industry: now, that support is greater than subsidies to agriculture, manufacturing and mining combined. This support is inefficient, in that the government expenditure for each additional patient treated in the private sector is well over the contemporary price paid for treating additional patients in the public sector. The additional government support is also probably impeding the ability of government to expand the public sector.

The Australian experience suggests that Canadians should be wary about allowing a significant private sector to develop in Canada, particularly if it seeks the level of subsidy that the Australian private sector has been able to garner.

Stephen J. Duckett

Professor of Health Policy

La Trobe University

Melbourne, Australia

\section{References}

1. Butler JR. Policy change and private health insurance: Did the cheapest policy do the trick? Aust Health Rev 2002;25(6): 33-41.

2. Duckett S. Private care and public waiting. Aust Health Rev 2005;29(1):87-93.

3. Hall J, De Abreu Lourenco R, Viney R. Carrots and sticks - the fall and fall of private health insurance in Australia. Health Econ 1999;8(8):653-60. 